\title{
Selection and Exploration of New Urbanization Path of Villages and Towns in Eco-conserving Division in Changchun
}

\author{
Limin Bai ${ }^{1,2, a}$, Chunliang Xiu, ${ }^{1, b}$ and Jing Lver, \\ ${ }^{1}$ Northeast Normal University,Changchun, Jilin,China;ddress of first author, including country \\ 2Jilin Jianzhu University, Changchun,Jilin,China \\ asunblm123@163.com, bhjm20042004@126.com, ‘wlaj97@163.com
}

\begin{abstract}
Keywords: eco-urbanization mode; new urbanization mode; local urbanization.
Abstract. Through the analysis on the Dahei Mountains research area of eco-conserving division in Changchun, this paper puts forward the exploration of selection mode of new urbanization path of villages and towns in conserving area, which that is are eco-urbanization mode, local urbanization and new urbanization mode with special tourism. The planning of villages and towns in conserving area should premise on "ecological view" and comprehensively propel ecological change of space structure, industrial structure and institutional and cultural structure to really realize the ecologicalization of new cities and towns.
\end{abstract}

\section{Introduction}

According to "National New Urbanization Planning (2014-2020)", now villages and towns across our country are all actively exploring various effective ways and modes to achieve this goal. However, whether a new urbanization path can be found to solve the contradiction both between land and development and the contradiction between zoology and development. The paper chose selects the eco-conserving division which is located in city suburbs and is full of contradiction of urbanization development in order to try to seek one urbanization path which is based base on the ecological view. Space planning which is based on the ecological view should take full consideration of basic rules of ecosystem and also should give consideration to rules of economic development. Through design methods and countermeasures of planning, such as ecological investigations, ecological justifications, ecological feedbacks and others, ecological environment development should be predicated, evaluated and controlled, and space pattern of villages and towns where function flow, material flow and energy flow can flow safely and orderly should be built to maximize economic benefit and minimize the loss of society and zoology so that function flow like material flow and energy flow can flow safely and orderly. Then the three ecosystems nature, economy and society which act on the land of villages and towns can achieve healthy and sustainable development, and the target of new urbanization can be realized.

\section{Location of Research Area}

Eco-conserving division in Changchun mainly refers to the district of Dahei Mountains in the southeast of Changchun, including it includes the Xinlicheng reservoir water conservation area, the Shitoukoumen reservoir water conservation area, Jingyuetan national forest park and other eco-conserving divisions which cover natural resources of central region of the Dahei Mountains ( fig. $1)$.

The Dahei Mountains are the Changbai Mountains extension, traverse the midland of Jilin province and are endowed with abundant vegetation and thick woods. They have superior natural ecological resources, they are material source and energy source of the whole ecosystem in Changchun and the midland of Jilin province, and are also the gene pools and energy pools to steady regional 


\section{Analysis on tThe Present Situation of Research Area Development}

\section{Analysis on the Present Situation of Ecological Security Pattern}

The main problem that the zoology of eco-conserving division in the Dahei Mountains in Changchun faces is the land for farmland, housing estate, holiday village and urban construction encroaching encroaches the existing natural environment land constantly, so the eco-conserving division in the Dahei Mountains presents a kind of development situation that artificialized patches surround natural patches. Meanwhile, due to further divisions of different levels for intercity traffic and urban and rural roads, the whole conserving area presents the growing trend of ecological fragmentation and artificialization, and the continuity and the integrality are destroyed severely.

\section{Analysis on the Present Situation of Villages and Towns Development}

Conserving area contains Jingyue town, Xinlihu town (fig. 2), Quannongshan town and other small

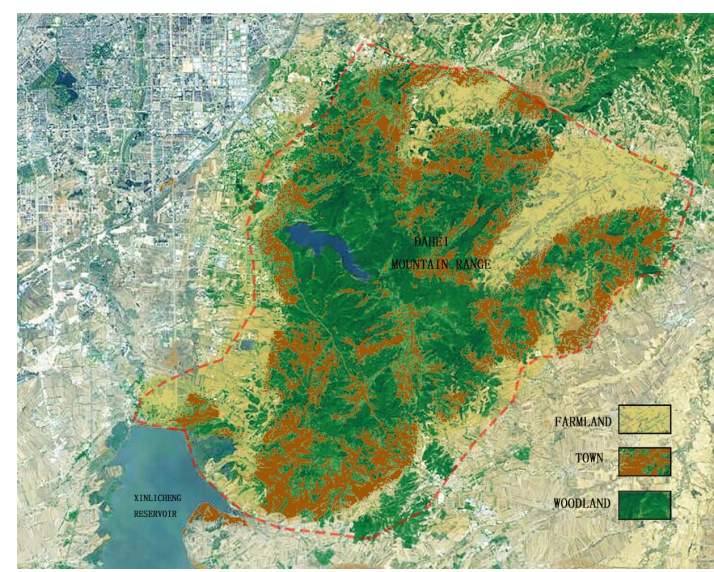

Fig .1 Location of the Dahei Mountains in Changchun

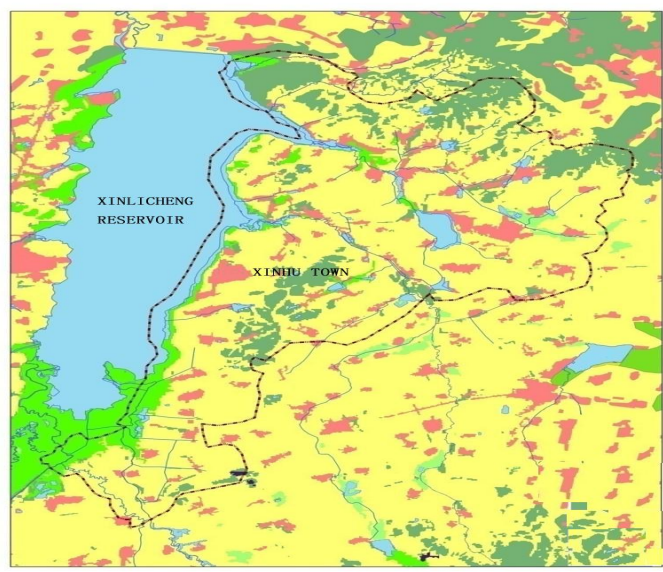

Fig..2 Land-use status of Xinhu Town

towns and villages. With the increase of human activity intensity and the development of villages and towns, construction land also has been increasing rapidly.increases. The whole conserving area presents the trend that artificialized patches erode natural patches. The fragmentation degree of landscape of the whole natural ecosystems becomes increasingly higher. As the important ecological protective screen in the urban area development of Changchun, the ecological functions of conversing area face severe the challenges.

\section{The mode selection of New Urbanization in the Villages and Towns of Convercing Area based on the Ecological View}

\section{Ecological Urbanization Mode}

As an important part of regional ecology, villages and towns of conserving area undertake the functions that offer ecological protective screen for cities and maintain ecological balance of areas. For a long time, low efficiency and extension of rural construction land have resulted in the terrible fact that lead to that ecological space becomes fragmentized and the pollution of small and decentralized rural industry with low efficiency is serious. This damages rural natural ecosystems immensely and deteriorates man-land relationship of rural areas. During "the Thirteenth Five Year", based on the concept of "intensive development", through designating all kinds of functional spaces of villages and towns, conserving area planning of villages and towns should control construction scale strictly to promote high efficiency and intensive use of villages and towns land. Based on the concept of "area fusion", the planning should intensify the relationship between ecosystems of villages and towns and ecological function plates nearby to blend in the large pattern of area ecologicalnetwork. Based on the concept of "green development", the planning should guide the industrial development with environment friendly of circulation pattern industry, ecological tourism, organic agriculture and other resources tobuild ecological industry system of villages and towns. 
Based on the concept of "low-carbon lifestyle", the construction of methane project and sewage purification system of villages should be completed, through establishing "rural culture greenway", villages and towns should be integrated into area leisure net and also the integration should be equipped with urban and rural public transport network and infrastructure of villages and towns(Xiao,2013).

\section{“Local Urbanization" ---- "Human Urbanization" -Centered Mode}

In the period of "the Thirteenth Five Year", in our country the urban-rural development enters the stage of transition and promotion in our country. This brings not only development opportunities for rural urbanization but also more challenges. The characteristic of rural transition is presenting the harmonious development from the past "economic growth guide" to urban-rural integration of "leave the land but not hometown". Both pPaying attention to the cultivation and effect of rurality in the planning and sparing no effort to solve the problem of "peri-urbanization" can to realize the deep urbanization of "people".

With the development of rural economy, peasants no longer migrate to large and medium-sized cities blindly but obtain employment, start businesses, produce and increase income relying on central villages and small towns in original places of residence. Meanwhile, the government completes infrastructure constantly, develops social public utilities, promotes the quality of farmers, changes their lifestyle and gradually forms new cities and towns to realize local non-agricultural employment and local citizenization, namely "local urbanization". Local urbanization is based on the development of agricultural economy and the improvement of agricultural modernization level. It should have industrial support. Only can Ddeveloping village industry can promote stable employment and make people work and live. Working in peace and contentment. and then living in peace and contentment. To realize local urbanization, the harmonious development of workers and peasants should be first realized. Therefore, urban-rural integration, urbanization of people and the harmonious development of workers and peasants are the basic meaning of local urbanization (Jiao,2015).

\section{New Urbanization Mode with Characteristic Tourism-Mode Based on Industry Domination}

Villages and towns with advantageous location of conserving area are situated in the suburbs of large cities. The selection of urbanization path can centre large cities to build new type cities and towns with tourism. Through building entertainment districts in Changchun suburbs and making the destination for recreation tourism, the villages and towns of conserving area will form the development mode of tourism towns. The central theme of making towns with characteristic tourism is to have specific features. That is to say, existing cities and towns should be transformed into new type cities and towns with specific features and also national customs should be integrated. At the same time, tourist scenic spot should be upgraded from "punctiform management" to "regional development" and the concept of "large brand" and "large scenic spot" should be established. Rural tourism development of Changchun should overcome the defects like that the management of present scenic spots being is punctiform and decentralized and should also enlarge the development scale and operating items of single scenic spot to form rural tourist clusters which are supported by central scenic spot. Furthermore, Or several scenic spots development with joint and clusters and gradually realize the upgrade from "punctiform management" to "regional development" to form regionally rural tourist industrial clusters and the share of large brands. This is beneficial to intensify the brands in scenic spot. Meanwhile, this can also realize the combination of regional joint development and industrial joint, and form "large brand" and "large scenic spot" with regional support and leading effect. The development mode of cities and towns with characteristic tourism is not only the simple tourism, but also should have certain basic industrial support. The cities and towns with characteristic tourism and basic industry are supporting each other, and then new urbanization can get the positive cycle development (Xin,2014). 


\section{Conclusions}

New urbanization should comprehensively promote the overall ecological change of space structure, industrial structure and institutional and cultural structure to truly realize the ecologicalization of new type cities and towns. New urbanization should integrate ecological theory and method into urban planning and construction and let zoology participate the whole process of compilation, conduct and management of planning. In the path selection and planning construction of new urbanization, zoology, "human urbanization", industrial selection and culture, and informatization should be emphasized, and also smart, green and low-carbon cities and towns which accord with new period and are suitable for human habitation should be built.

\section{Acknowledgements}

This work is supported by a grant from the Education Department in Jilin province([2016] No.163th), and by a grant from the Ministry of Housing and Urban-rural Development soft science project(2013-R2-20).

\section{References}

[1] Jiao Xiaoyun 2015. The Exploration and Analysis on the Delemma, Key Points and Countermeasures of Rural Local Urbanization in the Process of New Urbanization-Another Thought to Govern “Urban Diseases”.Urban Development Research, 22 volum, 2015 ( 1):35-39.

[2]Xiao Hongjuan.2013.The Strategy Research on Rural Transformation and Planning of the Pearl River Delta Region .Modern Urban Research (6): 41-45.

[3] Xin Yantao.2014. Research on Path and Strategies of China New Urbanization Mode: Liaoning University. 